\title{
Prioritising and tackling socio-economic inequalities in obesity
}

\author{
Anna Peeters ${ }^{*}$ and Kathryn Backholer
}

In countries with a high prevalence of obesity, socioeconomic disadvantage is associated with a greater risk of excess bodyweight. This is true for those living in more disadvantaged and rural areas, those with lower levels of education and income and a number of minority groups. As obesity is associated with a range of adverse health outcomes, this is likely to translate to a substantial burden to socio-economic inequalities in health. In addition, recent evidence suggests that as we act to prevent obesity, there is a risk that greater benefits will be experienced by the more well-off in society, leaving those with greater socio-economic disadvantage further behind. Here we discuss some of the recent trends in obesity and demonstrate why deeper consideration of differences in trends and intervention effectiveness across socioeconomic groups is critical.

In high income countries children and adults living with greater disadvantage also experience a higher risk of overweight and obesity than their more advantaged counterparts $[1,2]$. In low income countries the reverse is true. But in middle income countries, currently at the height of the epidemiological and nutrition transition, this is starting to switch to a negative gradient, similar to high income countries [3].

A greater burden of obesity is seen across a range of markers of socioeconomic position, with prevalence rates in Australia around double for Indigenous Australians and for those living in the most disadvantaged areas $[4,5]$. In high income countries children and adults with lower income and lower education generally experience more obesity, as do a number of ethnic minorities [1,2]. These inequalities matter as they will translate into inequalities in health, wellbeing and productivity outcomes, potentially further steepening the health and social gradients already observed in our communities. Further, as the greatest burden of excess weight falls on the more disadvantaged, if we are unable to reduce these inequalities we are unlikely

\footnotetext{
* Correspondence: Anna.peeters@bakeridi.edu.au

Obesity \& Population Health, Baker IDI Heart and Diabetes Institute, Melbourne, Australia
}

to substantially improve the population burden of obesityrelated disease and associated health care and productivity costs.

Last year, for the first time in 40 years there were reports from the United States that obesity prevalence in children had not increased in a number of states [6]. This was good news. However, in a number of the US jurisdictions reporting decreasing childhood obesity prevalence, there had been less or no progress in minority groups and for those living with greater poverty. In addition, a number of recent reports on childhood obesity trends around the world are suggesting that while obesity prevalence may no longer be increasing in more socio-economically advantaged children it is continuing to increase in those with greater disadvantage $[7,8]$. In Australia, we estimated that if current rates of weight gain continue, by 2025 almost half of Australian adults with a lower level of education would be living with obesity, compared to around one in three of those with the highest pels of education [9].

From these emerging data it appears we may be at a critical point in the obesity epidemic and acting now to prioritise decreasing socioeconomic inequalities in obesity may be more important than ever. Needless to say, we need continued investment into progressive social and economic policies that aim to reduce socio-economic inequalities in the fundamental determinants of good health such as education, housing, employment, and universal access to primary care [10-12]. But such policies need to coexist with a comprehensive range of actions that directly address socio-economic inequalities in obesity if we are to both prevent obesity and prevent a widening in socio-economic inequalities in health, wellbeing and productivity.

First we need to increase awareness, both in the need address socio-economic inequalities in weight and in what can be done to mitigate widening inequalities. This will necessitate the regular collection of national population level data for systematic and routine monitoring of inequalities of obesity and its risk factors. The importance 
of this is exemplified by reports such as those described above, wherein the conclusion based on total population data (general improvement in childhood obesity across the US) is quite different to that based on analyses by socioeconomic groups (continued worsening of obesity rates for groups with a lower socio-economic position). Furthermore, it is incumbent upon us, as epidemiologists and public health researchers, to continually communicate our research findings to those with influence over policy decisions so that inequalities become a more central focus in decision making. It remains a challenge to elevate the issue of socio-economic inequalities in obesity to commonplace political understanding and action. However, recent global reports demonstrate increasing recognition and acceptance of doing precisely this [10].

Second, we need to improve our understanding of what constitutes effective obesity prevention across different socio-economic groups. Globally the efforts to prevent and manage obesity are increasing. We know from other public health efforts that often the benefits are first experienced by the better off (those with relatively greater social and economic resources) before they are felt by the wider community (with more limited resources). This has been described for a number of public health issues, such as tobacco control [13].

We are starting to see evidence of this potential widening of socio-economic inequalities through policy implementation for obesity prevention. We have recently demonstrated that of the few obesity prevention interventions that have been evaluated across different socioeconomic groups, around half the interventions were found to be effective for groups with high socio-economic position only [14]. Rather than wait in hope that intervention effectiveness will eventually reach those from lower socio-economic groups, our challenge is to identify strategies that will enable us to prevent obesity across the whole population, with greater impact where it is most needed. A lot more work is required to do this, however we do know that interventions and policies that are more likely to affect the environments in which we live are also more likely to lead to equitable benefits [14] (Backholer in press). For example, following the 2006 smoke-free legislation in Scotland, there was a substantial fall in hospital admissions for myocardial infarction, which was consistent across all socio-economic groups [15]. Parallel conclusions have been drawn from the reduction of blood folate levels following fortification of cereal products and from the reduction of dental caries following water fluoridation $[16,17]$. We argue that greater consideration of some of the obesity prevention interventions that remove the structural barriers to healthy behavioural choices by changing our environment is needed. These include mandatory nutrition guidelines in all children's settings, restrictions to marketing of unhealthy food and drink, and pricing measures. Such interventions obviate the issues of uptake and compliance and thus more likely to be equitable across socio-economic groups. However, interventions of this type are politically difficult as they face civil libertarian arguments and involve multiple, often opposing, stakeholders. The challenge is to identify a constructive path forward so that broad action on obesity prevention continues at the same time as increasing our efforts to prioritise initiatives that mitigate socio-economic inequalities.

Third, this means that we need to give further thought to the combination of interventions we employ. We need to ensure that targeted approaches complement the (more politically palatable) information and knowledge -based policies, which are more likely to benefit those with higher socio-economic position (Backholer et al., in press). For example, complementary interventions might include social marketing or targeted nutrition education to augment menu energy labelling in fast-food restaurants. Similarly, they may involve using revenue raised from food or beverage taxes to subsidise obesity prevention interventions in disadvantaged neighbourhoods. Related to this, we need increased awareness of the potential for targeted approaches in the broader context of population-level obesity prevention, building on our understanding of the specific barriers to effective intervention among lower socio-economic groups.

Clearly, a comprehensive approach is required to galvanise action against socio-economic inequalities in weight. Importantly, each of these steps requires ongoing communication amongst all those who have the potential to influence population health and wellbeing. These include researchers, community leaders and organisations, industry and government and must not be limited to the health sector. We need to act now to ensure that in our efforts to prevent obesity we can also limit its impact on socio-economic inequalities in health, wellbeing and productivity.

\section{Competing interests}

The authors have no competing interests for this work.

\section{Authors' contributions}

$\mathrm{AP}$ and $\mathrm{KB}$ both contributed to the design, writing and editing of this piece.

\section{Acknowledgements}

The authors would like to thanks Genevieve Horne for her thoughtful comments on the manuscript.

\section{Funding}

KB was supported by a Post doctoral Research Fellowship from the National Heart Foundation of Australia (PH 12 M6824), AP was supported by a National Health and Medical Research Council Career Development Fellowship (1045456) and the Baker IDI. Funding support was also received from an Australian Research Council (ARC) Linkage grant (LP120100418), an Australian National Preventive Health Agency grant (188PEE2011) and the Victorian Government's Operational Infrastructure Support (OIS) Program. 
Received: 22 July 2014 Accepted: 30 July 2014

Published: 15 August 2014

\section{References}

1. Ball K, Crawford D: Socioeconomic status and weight change in adults: a review. Soc Sci Med 2005, 60(9):1987-2010.

2. Sobal J, Stunkard AJ: Socioeconomic status and obesity: a review of the literature. Psychol Bull 1989, 105(2):260-275.

3. Dinsa GD, Goryakin Y, Fumagalli E, Suhrcke M: Obesity and socioeconomic status in developing countries: a systematic review. Obes Rev 2012, 13(11):1067-1079.

4. Australian Institute of Health and Welfare: Are all Australian's gaining weight. Canberra: Australian Institute of Health and Welfare; 2003.

5. Australian Institute of Health and Welfare: Australia's Health. Canberra: Australian Institute of Health and Welfare; 2012.

6. Robert Wood Johnson Foundation: Declining childhood obesity rateswhere are we seeing signs of progress? Health Policy Snapshot - Childhood Obesity 2013, 1-2. http://www.rwjf.org/content/dam/farm/reports/ issue_briefs/2013/rwjf401163. 2013.

7. Frederick CB, Snellman K, Putnam RD: Increasing socioeconomic disparities in adolescent obesity. Proc Natl Acad Sci U S A 2014, 111(4):1338-1342.

8. Stamatakis E, Wardle J, Cole TJ: Childhood obesity and overweight prevalence trends in England: evidence for growing socioeconomic disparities. Int J Obes (Lond) 2010, 34(1):41-47.

9. Backholer K, Mannan HR, Magliano DJ, Walls HL, Stevenson C, Beauchamp A, Shaw JE, Peeters A: Projected socioeconomic disparities in the prevalence of obesity among Australian adults. Australian and New Zealand journal of public health 2012, 36(6):557-563.

10. CoSDo H: Closing the Gap in a Generation. Geneva: World Health Organisation; 2008.

11. Marmot M, Goldblatt P: Importance of monitoring health inequalities. BMJ 2013, 347:66576.

12. Di Cesare M, Khang YH, Asaria P, Di Cesare M, Khang YH, Asaria P, Blakely T, Cowan MJ, Farzadfar F, Guerrero R, lkeda N, Kyobutungi C, Msyamboza KP, Oum S, Lynch JW, Marmot MG, Ezzati M, Lancet NCD Action Group: Inequalities in non-communicable diseases and effective responses. Lancet 2013, 381(9866):585-597.

13. Huisman M, Kunst AE, Mackenbach JP: Educational inequalities in smoking among men and women aged 16 years and older in 11 European countries. Tobacco control 2005, 14(2):106-113.

14. Beauchamp A, Backholer K, Magliano D, Peeters A: The effect of obesity prevention interventions according to socioeconomic position: a systematic review. Obes Rev 2014, 15(7):541-54.

15. Emberson J, Whincup P, Morris R, Walker M, Ebrahim S: Evaluating the impact of population and high-risk strategies for the primary prevention of cardiovascular disease. Eur Heart J 2004, 25(6):484-491.

16. Riley JC, Lennon MA, Ellwood RP: The effect of water fluoridation and social inequalities on dental caries in 5-year-old children. Int J Epidemiol 1999, 28(2):300-305.

17. Dowd JB, Aiello AE: Did national folic acid fortification reduce socioeconomic and racial disparities in folate status in the US? Int $J$ Epidemiol 2008, 37(5):1059-1066.

\section{Submit your next manuscript to BioMed Central and take full advantage of:}

- Convenient online submission

- Thorough peer review

- No space constraints or color figure charges

- Immediate publication on acceptance

- Inclusion in PubMed, CAS, Scopus and Google Scholar

- Research which is freely available for redistribution 